\title{
A gestão semiplena e a participação popular na administração da saúde
}

\author{
Shared local health system management \\ and community participation in Brazil
}

Umberto Catarino Pessoto 1

Paulo Roberto do Nascimento 1

Luiza Sterman Heimann 1

\footnotetext{
${ }^{1}$ Núcleo de Investigação em Serviços e Sistemas de Saúde, Instituto de Saúde, Secretaria de Estado da Saúde de São Paulo.

Rua Santo Antônio 590 $4^{\circ}$ andar, São Paulo, SP 01314-000, Brasil.
}

\begin{abstract}
The introduction of the Unified Health System (SUS) by the Brazilian government has helped enhance community participation. A survey in 12 municipalities in different States of the country focused on the decentralization process implemented by the Federal government (Basic Operational Ruling NOB01/93). Based on the ruling's implementation, community participation has improved in the municipalities, the number of local health councils has increased, and more local people have become involved in the process. Another important aspect of the new health policy has been the direct influence of the local health councils in managing the system. Local health councils have thus been an efficient channel for community involvement. This paper discusses how the population has been represented in such councils in the wake of the decentralization process. The authors ask, what is the relationship between social democracy and political democracy, and what kind of state reform should be carried out?
\end{abstract}

Key words Consumer Participation; Health System; Decentralization

Resumo A construção do Sistema Único de Saúde imprimiu mudanças no aprofundamento do processo de participação da comunidade. Pesquisa realizada em doze municípios do país investigou o processo de descentralização suscitado pela vigência da Norma Operacional Básica 01/93. Entre os achados, encontramos um campo vasto de possibilidades à participação popular, originado na realidade local, impelido pela referida Norma. O espaço do controle público sobre o estado amplia-se, tanto quando se considera o aumento no número, quanto na busca de qualificação desses conselheiros. Os conselhos de saúde locais representam seguramente um mecanismo de participação. Cumpre, no entanto, discutir o caráter dessa representação e o alcance enquanto novo centro de poder decorrente da descentralização do sistema de saúde e da realidade política nacional. Novas questões são colocadas: a conexão entre democracia social e política; $a$ complexificação da sociedade levando a refletir sobre a configuração do Estado.

Palavras-chave Participação Comunitária; Sistema de Saúde; Descentralização 


\section{Introdução}

A descentralização constitui um tema central na discussão sobre a organização do sistema de saúde no Brasil. O Núcleo de Investigação em Serviços e Sistemas de Saúde (NISIS) do Instituto de Saúde da Secretaria de Estado da Saúde de São Paulo, considerando a vigência da Norma Operacional Básica (NOB) 01/93 (MS, 1993) como o momento que maiores contribuições apresentou à reorganização descentralizada do Sistema Único de Saúde (SUS), enveredou-se em 1997 e 1998 pela realização de uma pesquisa de abrangência nacional para estudar os efeitos que a gestão semiplena produziu no interior dos sistemas municipais de saúde (Heimann et al., 1998).

Foram selecionados doze municípios em todo o país que, no início da investigação, já reuniam as experiências de dois anos consecutivos de vigência da gestão semiplena preconizada pela NOB 01/93 (MS, 1993). Dos vários temas que a pesquisa abordou, discutiremos no presente artigo o referente à participação social e ao controle do público sobre o Estado, por intermédio da atuação dos conselhos de saúde, tomados em seus mecanismos constitutivos e participativos.

A municipalização da saúde no Brasil é fruto de um longo processo, iniciado na década de 50, pautada pelas concepções do chamado "sanitarismo desenvolvimentista" cujas teses foram aprovadas na III Conferência Nacional de Saúde em 1963. "A idéia era criar uma rede flexível, que em nível municipal se adequasse à realidade do município e que fosse se tornando mais complexa à medida que o próprio município se desenvolvesse..." (Fadul, 1978:74).

Mas é na década de 70 que surgem, em algumas cidades, experiências de formulações de políticas locais de saúde e de organização de redes municipais, seguindo os princípios da Conferência de Alma Ata. O I Encontro dos Secretários Municipais de Saúde do Sudeste aprova o "Memorial de Campinas" no qual constavam, entre outras reivindicações, a descentralização tributária, o aumento da dotação tributária das prefeituras para a saúde e a integração interinstitucional (Neto, 1991).

Concomitantemente à da política municipalista, havia a ação do Ministério da Previdência e Assistência Social em sentido contrário. O padrão de intervenção se evidenciava: (a) na centralização das decisões operacionais e financeiras no âmbito do Governo Federal, particularmente no Instituto Nacional de Assistência Médica e Previdência Social (INAMPS), o real executor da política para o setor; (b) no acento nas formas de financiamento que se apoiavam em recursos independentes do orçamento fiscal (via contribuições sociais, mais vulneráveis a crises econômicas); (c) na privatização, do ponto de vista da execução dos serviços, etc. (Draibe et al., 1990).

Esta tensão entre as esferas de governo na história da constituição do Estado brasileiro é, em verdade, marca do próprio processo dessa constituição (Cardoso, 1977). Desde o período colonial a dialética entre o Estado e os localismos, o Estado e a Sociedade Civil vem se manifestando, fazendo-se presente na Colônia, no Império e na República (Ferreira, 1986).

A década de oitenta, no setor saúde, é marcada pela 8a Conferência Nacional de Saúde (CNS), expressão máxima do movimento da reforma sanitária brasileira. A Assembléia Constituinte de 1986 a 1988 iria consubstanciar o jogo de forças nesse terreno. Após um longo processo de desconcentração dos serviços de saúde para os municípios e das tentativas de implementação de políticas coordenadas entre as três esferas de governo (Conselho Nacional de Administração de Saúde Previdenciária - CONASP -, Ações Integradas de Saúde - AIS -, Sistema Unificado e Descentralizado de Saúde - SUDS), com o fim de superar a grave crise fiscal de 1982, a Constituição Federal de 1988 consagra a descentralização, via municipalização dos serviços e das políticas de saúde, como uma das regras gerais do SUS. Uma extensa bibliografia atesta o grande esforço despendido nas instituições de ensino, de pesquisa e nos serviços para esclarecer a importância e o formato descentralizado mais adequado à realidade brasileira (Arretche, 1997; Gerschman \& Vianna, 1997; Hortale, 1997; Figueiredo et al., 1998).

É sempre relevante salientar que esse processo deu-se num contexto geral de pressões da sociedade pela democratização do Estado, que pode ser exemplificado pelas grandes greves de 1978/1979 e 1981/1982, pelas eleições diretas para governadores dos estados da federação, a constituição das centrais sindicais, os movimentos pelas “Diretas-Já”, pela constituinte, pelas eleições dos prefeitos de capitais dos estados, das estâncias hidrominerais e cidades portuárias, e, por fim, pelas eleições diretas para Presidência da República em 1989. No entanto, a municipalização só pode ser entendida como processo verdadeiramente descentralizador, na medida em que fortaleça os poderes locais e aprofunde a prática da "gestão descentralizada e participativa no SUS", exercendo o "controle social sobre a produção e consumo dos serviços de saúde”, como reza o Relatório Final da 8a CNS (Heimann et al., 1992:39). 
Na década de 90, sob inspiração das Leis 8.080/90 (Brasil, 1990a) e 8.142/90 (Brasil, 1990 b), é elaborada a Norma Operacional Básica 01/93 (NOB 01/93) (MS, 1993), a qual previa três formas de gestão: incipiente, parcial e semiplena. Para se habilitarem a qualquer uma delas, era necessário que os municípios, dentre outras coisas, constituíssem Conselhos Municipais de Saúde (CMS): espaços políticos públicos onde são representados, formal e publicamente, os interesses dos representantes da população (Cortez, 1998).

Os CMS, ao contrário das antigas Comissões Interinstitucionais Municipais de Saúde (CIMS), são instâncias deliberativas e paritárias onde se dá a relação entre os representantes dos usuários e do setor dos prestadores, aqui incluídos governo, funcionários dos serviços, associações de profissionais que atuam na rede pública de serviços e os prestadores conveniados e contratados. O caráter paritário e deliberativo foi ratificado e reforçado na NOB 01/93 (MS, 1993). Portanto, o escopo geral da pesquisa foi verificar de que maneira essa norma influiu no aprimoramento do conteúdo e das formas de participação nas decisões das políticas municipais de saúde.

\section{Objetivo}

Interessava-nos esclarecer como a gestão descentralizada dos serviços de saúde conduziu à adoção de estruturas e práticas voltadas para o incremento da participação da comunidade na administração dos sistemas municipais de saúde. Foram então formuladas três questões de investigação voltadas a revelar (1) se novos mecanismos de participação da comunidade haviam sido criados, (2) se houve mudanças nos mecanismos de definição da representação da comunidade nos conselhos e como estes sofreram mudanças em sua composição e (3) se as deliberações do Conselho e das conferências municipais eram incorporadas ao processo de planejamento e programação do sistema local de saúde.

\section{Material e método}

Dos 124 municípios incluídos na condição de gestão semiplena, em agosto de 1996, apenas 24 completariam, em dezembro do mesmo ano, dois anos nesta nova realidade. Estes municípios, portanto, foram considerados o universo de nosso estudo, uma vez que o tempo decorrido permitiria observar mudanças significativas decorrentes do novo processo de gestão. Doze foram selecionados para estudo, de acordo com os seguintes critérios: municípios localizados em diferentes regiões do país; municípios localizados em estados que vinham implementando diferentes modelos de gestão descentralizada do sistema de saúde; municípios de diferentes portes, em termos de população; municípios localizados em diferentes regiões do estado: áreas metropolitanas e interior; municípios de diferentes portes, em termos de complexidade dos serviços. Os municípios selecionados foram: Natal (Rio Grande do Norte); Petrolina (Pernambuco); Blumenau (Santa Catarina); Panambi (Rio Grande do Sul); Quixadá e Fortim (Ceará); Belo Horizonte e Sete Lagoas (Minas Gerais); Santos, Diadema, Mauá e Votorantim (São Paulo).

Adotamos o método de estudo de caso, o que nos permitiria organizar os dados sociais preservando caráter unitário do objeto social estudado, ao mesmo tempo em que poderíamos rejeitar a "falsa dicotomia entre estudos qualitativos e quantitativos, ou entre pontos de vista estatístico e não estatístico" (Goode \& Hatt, 1977:398). O desenho da investigação constou da observação dos momentos anterior e posterior à adesão à condição de gestão semiplena.

O material utilizado constou de: documentos da legislação, relatórios de gestão, atas de reunião do CMS, relatórios das Conferências Municipais de Saúde e planos municipais de saúde; bem como, aplicação de questionários. Foram elaborados três questionários específicos: um para o ex-Secretário Municipal de Saúde, responsável pela gestão no período em que o município aderiu à condição de gestão semiplena; outro para o Secretário Municipal por ocasião da pesquisa; e um terceiro, para um membro do CMS, representante da população. Elaborou-se, também, um roteiro de observação para as visitas aos municípios, que depois foi consolidado em um Relatório de Campo.

\section{Resultados}

Desde 1991 vinham sendo implantados o Conselho Nacional, os conselhos estaduais e, num número crescente de cidades, os conselhos municipais de saúde. Segundo a Lei 8.142 (Brasil, 1990b) a representação dos usuários nos conselhos deve ser paritária em relação ao conjunto dos demais segmentos. Para que os municípios se habilitassem a assumir as formas mais avançadas de gestão descentralizada, que lhes conferiam maior autonomia, a NOB 01/93 (MS, 1993) reforçou a exigência da criação dos 
CMS, entendidos como "foros de negociação e deliberação".

As questões formuladas na pesquisa tentaram responder à hipótese de que a habilitação municipal à forma mais avançada de gestão do sistema de saúde foi um fator de estímulo à maior participação da comunidade nos fóruns institucionais de representação, previstos no ordenamento legal do SUS.

Nos 12 municípios, verificamos que a formação dos conselhos municipais fora anterior à edição da NOB 01/93 (MS, 1993). No entanto, a assunção da gestão semiplena trouxera maior aporte de recursos financeiros para esses municípios, além de mais autonomia na gestão dos recursos. Este fato se mostrou, inegavelmente, um motor para o incremento da participação, bem como de sua qualificação, especialmente em temas que até recentemente não faziam parte da prática dos movimentos organizados da sociedade brasileira, como por exemplo, a formulação de política, a leitura crítica de planos e relatórios de saúde e, por fim, o acompanhamento dos balanços financeiros e orçamentários de órgãos dos poderes públicos no Brasil.

Verificamos no decorrer da pesquisa que, em metade dos municípios estudados, ocorreu a criação de outros mecanismos de participação. Entenda-se por outros mecanismos toda e qualquer forma de fórum que não o Conselho ou a Conferência Municipal de Saúde, exigidos pela legislação.

Em Diadema, Fortim, Quixadá e Votorantim, os conselhos locais de saúde, vinculados a unidades básicas de saúde, foram criados após esses municípios se habilitarem à gestão semiplena. Em Belo Horizonte, Natal, Mauá e Santos os conselhos locais de saúde já existiam anteriormente à edição da NOB 01/93 (MS, 1993) (bem como os fóruns mais amplos que denominamos de plenárias de saúde), refletindo uma organização mais forte da população local de modo geral e, em particular, em torno das questões ligadas à saúde. Em Natal e Sete Lagoas foram criados os conselhos distritais. Em Belo Horizonte houve ampliação do número de conselhos distritais, de 2 para 9, abrangendo assim a totalidade dos distritos de saúde do município, além de um aumento de 20 para 108 no número de conselhos locais, em um total de 140 unidades de saúde.

Em Blumenau não havia conselhos locais, e tampouco estavam em iminência de serem criados, segundo o presidente do CMS (da representação da CIST - Comissão Intersindical de Saúde do Trabalhador), apesar da solicitação do próprio Conselho Municipal. Todavia, é neces- sário salientar que as associações de bairro, cuja extensão horizontal e força aglutinadora lhes permitiam influir, muitas vezes decisivamente, nas eleições para prefeito e vereadores, cumpriam um papel relevante no controle dos serviços públicos adstritos à sua área de atuação.

Como podemos perceber, os conselhos locais de saúde foram as instâncias que mais se desenvolveram nos municípios pesquisados (Tabela 1), permitindo assim inferir que tais organizações tendem a se disseminar mais facilmente e que, portanto, pode ser uma conseqüência da assunção da gestão semiplena pelos municípios. Ao contrário, as outras duas instâncias, conselho distrital e plenária, por sua natureza mais abrangente, tendem a ser muito mais determinadas pela própria capacidade prévia de organização da sociedade do que pelas normas e diretrizes de uma forma específica de gestão do sistema de saúde.

A expansão do número de conselhos produz a expansão concomitante do número de pessoas direta ou indiretamente envolvidas com as instituições públicas de controle social. Se esse aumento não é condição suficiente, é todavia condição necessária para uma maior efetividade da participação enquanto instrumento de democratização do Estado e da própria sociedade, como sugerem O’Dwyer \& Moysés (1998), inclusive citando A. I. Carvalho, que em 1995 já contabilizava 70 mil pessoas, em todo o país, diretamente envolvidas nos conselhos. Não obstante, importante será, em pesquisa futura, investigar os poderes e conteúdos dessas representações.

Outro aspecto verificado pela pesquisa é que, após a adesão, em todos os municípios ocorreram mudanças na legislação relativa aos CMS, apontando para o seu fortalecimento. Dois aspectos mereceram especial atenção dos investigadores: a representação na composição dos conselhos e o exercício de sua presidência.

Com a gestão semiplena, cinco municípios efetuaram alterações na composição do CMS voltadas para o aumento da representatividade da comunidade. Blumenau e Belo Horizonte aumentaram o número de conselheiros com o propósito de contemplar representantes de novos atores que começaram a discutir os planos de saúde nas conferências municipais de saúde. Em Blumenau foram: a Comissão Intersindical de Saúde do Trabalhador e das associações religiosas que desenvolvem atividades assistenciais de saúde, além de ampliar a representação da Associação de Moradores e da Rede Feminina de Combate ao Câncer. Em Belo Horizonte criou-se a representação dos conselheiros oriundos dos Conselhos Distritais. Ha- 
via, também, a Plenária Inter-conselhos, em que eram discutidas as principais demandas para o Orçamento Participativo, mecanismo instituído pela gestão municipal de 1993/1996. A preservação do paritarismo no conselho de saúde foi solucionada pela incorporação de mais representantes da secretaria, dos funcionários e das associações representativas dos profissionais da saúde. Não foram detectadas pressões dos prestadores privados por ampliação da sua representação.

Em Quixadá é instaurado o tripartismo e a paridade; em Petrolina inclui-se a participação dos funcionários da saúde no conselho; e em Santos institui-se a paridade. Os municípios que não apresentaram mudanças na composição dos conselhos, em verdade encontravamse de acordo com a legislação que rege a sua formação.

Neste aspecto específico da representatividade no CMS, são necessárias outras investigações, que extrapolem o âmbito próprio da avaliação do sistema de saúde, e que seja capaz de responder qual a real dimensão da representatividade da sociedade civil organizada nos CMS, ou seja, uma investigação que busque verificar em que proporção os interesses expressos em uma determinada municipalidade contam, de fato, com assento no conselho.

Em Blumenau (em 1997), Diadema, Panambi, Santos e Quixadá o presidente do CMS passou a ser eleito, deixando este cargo de ser prerrogativa do Secretário de Saúde. Fortim, recentemente emancipado, já adotara a eleição como forma de escolha do Presidente, mesmo antes da adesão à gestão semiplena. Em Belo Horizonte, a V Conferência Municipal de Saúde, de 1996, resolveu enviar à Câmara Municipal um projeto de lei alterando a forma de escolha do cargo, que passaria a ser feita via eleição pelos conselheiros.

Como se vê, a forma de gestão adotada parece influir diretamente na quebra da prerrogativa da Presidência do Conselho ao secretário municipal de saúde. Dos doze municípios estudados, em onze o secretário de saúde era o presidente "natural" do Conselho. Após a adesão, os regimentos internos foram alterados em seis municípios, de modo a instituir a eleição entre os pares. O controle sobre o Fundo Municipal de Saúde pode ter importância fundamental nessa mudança.

Essa mudança no próprio controle do funcionamento do CMS, provavelmente, vai alterar o grau de dependência dos representantes dos usuários em relação ao saber e poder médicos, geralmente centralizados na figura do secretário de saúde, até recentemente o "presi-

\begin{tabular}{|c|c|c|c|}
\hline \multicolumn{4}{|c|}{$\begin{array}{l}\text { Municípios da pesquisa segundo existência de outras instâncias de participação } \\
\text { no setor, além do Conselho Municipal de Saúde. }\end{array}$} \\
\hline Municípios & $\begin{array}{l}\text { Conselho Local } \\
\text { de Saúde }\end{array}$ & $\begin{array}{l}\text { Conselho Distrital } \\
\text { de Saúde }\end{array}$ & $\begin{array}{l}\text { Plenária } \\
\text { de Saúde }\end{array}$ \\
\hline Fortim & $\operatorname{Sim} *$ & Não & Não \\
\hline Quixadá & $\operatorname{Sim} *$ & Não & Não \\
\hline Natal & Sim & $\operatorname{Sim} *$ & Não \\
\hline Petrolina & Não & Não & Não \\
\hline Sete Lagoas & Não & $\operatorname{Sim} *$ & Não \\
\hline Blumenau & Não & Não & Não \\
\hline Diadema & $\operatorname{Sim} *$ & Não & $\begin{array}{l}\text { Conselho } \\
\text { Popular }\end{array}$ \\
\hline Mauá & Sim & Não & Sim \\
\hline Santos & $\operatorname{Sim}$ & Não & Sim \\
\hline Votorantim & $\operatorname{Sim} *$ & Não & Não \\
\hline Belo Horizonte & Sim & Sim & Sim \\
\hline Panambi & Não & Não & Não \\
\hline
\end{tabular}

Fonte: Entrevistas e atas de conselhos municipais.

* Conselhos instituídos após a adesão à NOB 01/93.

dente natural" do CMS. Para além da mera idéia de cooptação e controle do Estado sobre a representação em espaços institucionais (Dallari et al., 1996) que certamente persiste em certas parcelas dos movimentos e da intelectualidade que estuda o problema, essa "quebra de prerrogativa" sugere maior autonomia e maturidade dos movimentos sociais nos espaços de participação que foram sendo conquistados nos últimos vinte anos.

Por ser um dado novo, essa questão merece, também, pesquisas e reflexão sobre pelo menos dois aspectos: (1) se os conselhos passaram a ter maior poder de decisão após a eleição de sua presidência; e (2) se, e de que maneira, a presidência, quando e onde é prerrogativa do secretário de saúde, inibe o poder de decisão do Conselho.

Aquele fato, notável, adquire maior envergadura quando o analisamos associado a um outro dado captado pela pesquisa, qual seja, a crescente e intensa mobilização dos conselheiros na qualificação da participação nesse tipo de espaço político e técnico-institucional. Frente à insuficiência de informação e formação da população motivada a participar, os conselheiros vêm respondendo com a criação de câmaras técnicas, verificada em sete municípios, que visam aprofundar os temas mais importantes. Em Belo Horizonte, em 1994, os conselheiros se dividiram em grupos para discutir Financiamento, Recursos Humanos, Controle e 
Avaliação, Comunicação e Municipalização. Em outros municípios, os CMS buscaram assessorias técnicas e realizaram vários cursos de formação. Em Santos, era particularmente notável o dinamismo dos conselheiros, que participavam de palestras, debates, cursos e promoviam eventos, utilizando os meios de comunicação para divulgar seu trabalho. Em Blumenau, o CMS fez parceria com uma emissora local de rádio, onde é apresentado um programa semanal de uma hora de duração, em que são discutidos temas relacionados aos problemas de saúde do município.

Com a exceção de Votorantim e Panambi, todos os municípios constituíram câmaras ou comissões técnicas específicas para acompanhamento das ações de saúde do executivo. Dos que assim procederam, apenas Sete Lagoas não chegou a promover cursos para capacitação de seus conselheiros. Ocorreu um evidente processo de desenvolvimento e qualificação dos conselhos de saúde. Este fato está fortemente associado à forma de gestão semiplena.

Devemos ainda registrar as tentativas mais recentes de articulação nacional dos conselhos de saúde, objetivando seu fortalecimento perante os três níveis do poder executivo e reivindicando oportunidades de formação. Mediante estas iniciativas, os conselheiros mostraram sua preocupação em se tornarem aptos a participar de instâncias que exigem discussões de conteúdo técnico e que exercem um papel crítico em relação ao poder executivo, como é o caso dos CMS. Desse fato deriva uma pergunta ainda não respondida: qual o grau de autonomia técnica e teórica que os cursos têm proporcionado aos conselheiros, de modo a quebrar a dependência em relação aos técnicos das secretarias de saúde, no que se refere à formulação de políticas públicas de saúde?

A terceira e última pergunta que nos propusemos a responder dizia respeito ao processo de incorporação das deliberações do CMS ao planejamento e programação do sistema de saúde do município. Sua resposta foi prejudicada pelas próprias deficiências do executivo municipal. Observamos que o processo de planejamento e programação não pode ser tomado como indicador da permeabilidade do estado em relação à participação, por ser peça frágil nos municípios estudados. Não encontramos planos de saúde em que constassem objetivos e metas que pudessem ser acompanhados regularmente. Esses documentos de governo, quando existem, mais parecem cartas de intenções; mais se aproximam a relatos descritivos da rede e das ações dos serviços do que propriamente planos e relatórios de gestão es- truturados, qualquer que seja a teoria do planejamento em que ancoremos. Esse problema da organização das atividades e das informações dos serviços públicos é um dos grandes "nós" a serem desatados na administração pública brasileira.

De qualquer maneira, nas entrevistas com os conselheiros e na comparação entre os relatórios das conferências e atas dos conselhos com os planos de saúde e relatórios de gestão do governo, verificamos a incorporação de, em média, $70 \%$ das reivindicações, sugestões e deliberações dos conselhos de saúde, como também das conferências municipais de saúde. As novas exigências da Programação Pactuada e Integrada (PPI), estabelecida pela Norma Operacional Básica 01/96 (NOB 01/96) (MS, 1997), são mais uma tentativa de normalizar e organizar as informações municipais. Com a melhor qualificação dos conselheiros no acompanhamento dos negócios do executivo, possivelmente àquela norma venha se agregar a necessidade imperiosa da transparência das contas públicas.

\section{Discussão}

O tema da participação da população nos diversos foros de decisão na sociedade brasileira tem sido foco de interesse de muitos estudiosos. Os estudos surgem no final da década de 70 e têm como objeto a natureza dos movimentos populares, suas especificidades e demandas. A literatura é vasta e preencheu muitas lacunas na bibliografia brasileira, notadamente na década de 80 (Silva \& Ribeiro, 1984). Como não poderia deixar de ser, a questão dos conselhos de saúde, sejam eles de nível federal, estadual ou municipal, insere-se no tema da redemocratização do Estado e da sociedade brasileiros após a ditadura militar.

Apesar de a experiência dos conselhos não ser nova na história das democracias ocidentais, no Brasil ela é relativamente recente e tem suscitado algumas questões teóricas interessantes, principalmente por quem já participou como conselheiro ou por quem estava do outro lado da mesa, particularmente, os secretários municipais de saúde.

Um dos problemas levantados de grande relevância é a possível contradição entre uma plataforma de governo legitimamente sufragada nas urnas e as deliberações dos CMS (Heimann et al., 1997). Um outro problema é sobre a natureza da participação nos conselhos, ou seja, quem e de que forma o conselheiro representa. Uma outra questão - que em verdade 
não é um problema mas uma confusão - refere-se à forma de democracia que o conselho expressa: democracia direta em oposição à democracia representativa. Essa questão, apesar de não comportar dúvidas no campo teórico das Ciências Sociais, ainda aparece nos encontros e debates entre os profissionais da saúde.

O problema da democracia é um tema central da teoria política contemporânea, e, nessa arena, várias correntes de pensamento estão em litígio. Aos liberais, por exemplo, basta a própria noção de participação política expressa no sufrágio universal, entendido como um valor em si. Dessa maneira essa orientação teórica concentra suas reflexões no âmbito da esfera da política, desprezando assim a questão da participação nas esferas das relações sociais e econômicas, mormente quando se classifica a participação enquanto mero fator de garantia do equilíbrio do sistema e a democracia como simples regras de um jogo. Jügem Habermas (1979), um dos principais críticos dessa redução da democracia feita pelos liberais, coloca uma questão interessante quando afirma que a democracia trabalha a favor da autodeterminação, e neste sentido a participação política e autodeterminação coincidem, e que neste caso o importante é saber se a participação política promove ou não o desenvolvimento de tendências democráticas.

É justamente neste aspecto que assume importância o surgimento de uma esfera cuja ordenação jurídica tem perdido o caráter de direito privado sem que, tampouco, possa reduzir-se às categorias do direito público. Essa esfera se constitui em uma espécie de franja de interseção entre o que se entende por Estado, ou público, e a sociedade civil ou espaço privado. No desenvolvimento histórico do Estado moderno, a saúde foi gradativamente passando da esfera do privado para se tornar uma preocupação e objeto de intervenção da esfera do público ou do Estado, num processo ainda não esgotado. No Brasil, esse é um fenômeno jurídico recente, dado que a saúde foi considerada um direito do cidadão e dever do Estado somente a partir da Constituição de 1988.

Portanto, na perspectiva de tentar explicar o fenômeno da participação nos conselhos, recorremos a um teórico italiano de grande trânsito entre as diversas correntes políticas e que tem contribuído muito para a discussão sobre a democracia, Norberto Bobbio. Ficamos, pois, com um autor que discute a questão da democracia e da participação dentro do âmbito próprio da sociedade capitalista contemporânea.

A primeira contribuição de Bobbio sobre a questão da democracia representativa versus democracia direta é justamente desmistificar a falsa contradição entre uma e outra, uma vez que ambas não são alternativas mutuamente excludentes, mas são dois sistemas que podem se integrar reciprocamente, conformando o que ele chama de democracia integral (Bobbio, 1986). Porém, a única forma de democracia direta possível no atual estágio de desenvolvimento das sociedades modernas seria o referendum. Mesmo os conselhos não se conformariam enquanto instrumentos de democracia direta, já que os mesmos se instituem via representação. Aqui se resolve a confusão citada anteriormente.

O que estaria ocorrendo no Brasil, à semelhança da Itália dos anos 70, é a ampliação do processo de democratização. Este processo de democratização é entendido como expansão do poder ascendente, que se estende da esfera das relações políticas (em que o indivíduo é entendido em seu papel de cidadão, na clássica equação um indivíduo um voto) para a esfera das relações sociais em que o indivíduo é considerado na variedade de seus papéis e status (pai, filho, consumidor, gestor dos serviços públicos e usuário). Esse processo de democratização implica não uma passagem da democracia representativa para a democracia direta e sim da democracia política para a democracia social.

Esta extensão do poder ascendente, que até agora havia ocupado o campo da sociedade política, vai aos poucos se disseminando para o campo da sociedade civil nas suas várias articulações - escolas, fábricas, serviços públicos (Bobbio, 1986).

Ou seja, aqui fica claro que o pensador italiano reconhece a existência de vários centros de poder além do poder político propriamente dito, que reside na sociedade política ou Estado. Segundo esse mesmo raciocínio, coloca-se o problema do desenvolvimento democrático da sociedade. Neste caso, tanto na Itália de Bobbio quanto no Brasil pós-1988, não seria mais a questão do aumento do número de eleitores e sim dos espaços em que o cidadão pode exercer seu próprio poder de eleitor que deveria ser objeto de atenção. O ângulo visual se desloca do Estado para a sociedade civil. Neste aspecto, assume exemplaridade o surgimento dos conselhos de escolas e, em especial os conselhos de saúde, sejam municipais, distritais ou locais.

Considerando-se o conselho de saúde um novo centro de poder, haveria necessidade de se desvendarem as formas de representação que se explicitam em seu interior. Para essa verificação deve-se, sempre segundo Bobbio (1986), 
abordar dois temas: os poderes do representante e o conteúdo da representação.

A abordagem do tema dos poderes do representante, inserido na problemática mais ampla da representação política, deveria responder à seguinte pergunta: o conselheiro representa como delegado ou como fiduciário? Se delegado, ele é um mero porta-voz de seus representados, portanto com mandato limitado e revogável (mandato imperativo). Se fiduciário, ele tem poder de agir com certa liberdade e de interpretar os interesses dos representados e, portanto, não tem vínculo de mandato.

O outro problema, do conteúdo da representação, refere-se a que interesses o conselheiro está vinculado: interesses gerais ou particulares. A representação dos interesses gerais é, por exemplo, o caso clássico da representação legislativa; a representação dos interesses particulares expressa-se na representação por categorias profissionais (médicos, enfermeiras, metalúrgicos etc.) ou por papéis ou funções sociais desempenhadas (mulheres, deficientes físicos, negros etc.).

Tomando-se estas questões em seu conjunto, pensamos que pode ser resolvido o problema da contradição levantada entre o programa de governo legitimamente eleito e os poderes dos conselhos de saúde. Em verdade é uma falsa dicotomia, pois o poder dos conselhos não sub-roga o poder dos executivos, nem dos legislativos, porque o entendemos como fator integrante do processo de democratização da sociedade e também do Estado. Neste caso, reconhece-se a existência de outros centros de poder, tão legítimos e necessários quanto o centro do poder político de Estado. Esse é um movimento necessário caso tenhamos como objetivo a implantação de uma sociedade democrática pluralista, em que o poder autocrático seja contrastado pelo poder ascendente, ao mesmo tempo que o poder monocrático é confrontado pelos vários centros de poder emergentes e derivados da auto-organização da sociedade civil.

Também entendemos que, por seu caráter deliberativo e de controle sobre o Fundo Municipal de Saúde, os conselhos de saúde começam a tocar um dos grandes blocos de poder descendente e hierárquico que ainda estava imune ao processo de democratização: a administração pública (o outro bloco, para Bobbio, é a grande empresa).

É certo que a discussão acerca do tema da participação não se esgota, e nem deveria, tomando-se apenas uma abordagem teórica como fizemos neste caso. Recorrendo a Habermas temos outro tipo de abordagem, mais genérica e abrangente na discussão sobre o Estado de direito liberal e da democracia. Para o autor, o próprio Estado transfere aos grupos de interesses privados certas funções e, em alguns casos, "amplos setores da administração estatal direta e indireta têm sido subtraídos ao Estado e têm-se convertido em elementos de um sistema administrativo, paralelo ao estatal, que emana dos diversos agrupamentos sociais" (Werner Weber, apud Habermas, 1979:382) (grifos nossos). Nesta perspectiva, o contato do cidadão com o Estado dá-se nos serviços da administração, e a atitude desse cidadão ante o Estado é de quem recebe um benefício e, portanto, não precisamente de participação política. É de quem espera receber assistência, sem querer impor decisões.

Assumir essa orientação teórica seria, necessariamente, empreender uma crítica ao estado capitalista contemporâneo. Seria uma tarefa árdua e complexa que se distanciaria muito da abrangência desse estudo.

\section{Agradecimentos}

Os autores agradecem o financiamento desta pesquisa pelo International Development Research Center, Canadá. Gerência Financeira: Rede de Investigação em Sistemas e Serviços de Saúde do Cone Sul. 


\section{Referências}

ARRETCHE, M. T. S., 1997. O sistema de proteção social brasileiro: Em direção a um modelo descentralizado. São Paulo em Perspectiva, 11:20-31.

BOBBIO, N., 1986. O Futuro da Democracia. Rio de Janeiro: Editora Paz e Terra.

BRASIL, 1990a. Lei no 8.080, de 19 de Setembro de 1990. Lei Orgânica da Saúde. Dispõe sobre as Condições para a Promoção, Proteção e Recuperação da Saúde, a Organização e o Funcionamento dos Serviços Correspondentes e dá Outras Providências. Diário Oficial da República Federativa do Brasil, Brasília, DF, v. 128, n.182, pp. 18055-18059, 20 set. Seção I, pt. 1 .

BRASIL, 1990b. Lei no 8.142, de 28 de Dezembro de 1990. Dispõe sobre a Participação da Comunidade na Gestão do Sistema Único de Saúde (SUS) e sobre as Transferências Intergovernamentais de Recursos Financeiros na Área da Saúde e dá Outras Providências. 02 de Outubro de $2000<$ http:// www.saude.gov.br>.

CARDOSO, F. H., 1977. O Estado na América Latina. In: O Estado na América Latina. (P. S. Pinheiro, ed.), v. 2, pp. 77-99, São Paulo: Centro de Estudos e Cultura Contemporânea/Editora Paz e Terra.

CORTEZ, S. M. V., 1998. Conselhos municipais de saúde: A possibilidade dos usuários participarem e os determinantes da participação. Ciência \& Saúde Coletiva, 3:5-17.

DALLARI, S. G.; ADORNO, R. C. F; FARIA, M. M.; SHUQAIR, N. S. M. S. A. Q. \& TREWIKOWSKI, S., 1996. O direito à saúde na visão de um conselho municipal de saúde. Cadernos de Saúde Pública, 12:531-540.

DRAIBE, S. M.; VIANA, A. L. D. \& SILVA, P. L. B., 1990. Desenvolvimento de Políticas de Saúde nos Anos 80: O Caso Brasileiro. Campinas: Núcleo de Estudos de Políticas Públicas, Universidade Estadual de Campinas/Organização Pan-Americana de Saúde. (mimeo.)

FADUL, W., 1978. Minha política nacional de saúde. Saúde em Debate, 7:67-76.

FERREIRA, O. S., 1986. A Teoria da "Coisa Nossa" ou a Visão do Público como Negócio Particular. O Estado e a Oligarquia, e o Sistema. São Paulo: Edições GRD.

FIGUEIREDO, A. M.; ABREU, D. M. X.; FRANÇA, S. B.; SOMARRIBA, M. M. G. \& BELISÁRIO, S. A., 1998. Descentralização da saúde e poder local em Minas Gerais. Revista de Administração Pública, 32: 27-41.
GERSCHMAN, S. \& VIANNA, M. L. W., 1997. A Miragem da Pós-modernidade. Democracia e Políticas Sociais no Contexto da Globalização. Rio de Janeiro: Editora Fiocruz.

GOODE, W. J. \& HATT, P. K., 1977. Métodos em Pesquisa Social. São Paulo: Companhia Editora Nacional.

HABERMAS, J., 1979. Participação política. In: Política e Sociedade. (F. H. Cardoso \& C. E. Martins, org.), v. 1, pp. 375-388, São Paulo: Companhia Editora Nacional.

HEIMANN, L. S.; CARVALHEIRO, J. R.; DONATO, A. F.; IBANHES, L. C.; LOBO, E. F. \& PESSOTO, U. C., 1992. O Município e a Saúde. São Paulo: Editora Hucitec.

HEIMANN, L. S.; CASTRO, I. E. N.; KAYANO, J.; ROCHA, J. L.; TERENCE, M. F.; LUIZ, O. C.; FRAISSAT, R. A.; PESSOTO, U. C. \& JUNQUEIRA, V., 1998. A Descentralização do Sistema de Saúde no Brasil - Uma Proposta de Investigação sobre Impacto de Políticas. São Paulo: Instituto de Saúde, Secretaria Estadual de Saúde de São Paulo. (mimeo.)

HEIMANN, L. S.; KAYANO, J.; FRAISSAT, R. A.; PESSOTO, U. C., 1997. Reforma do Estado e reforma setorial no Brasil: Novos modelos de gestão. In: V Congresso Brasileiro de Saúde Coletiva, Anais, p. 277. Rio de Janeiro: ABRASCO.

HORTALE, V. A., 1997. O conceito de descentralização aplicado aos serviços de saúde: Dimensões, padrões e regularidades. Revista de Administração Pública, 31:23-35.

MS (Ministério da Saúde), 1993. Portaria MS no 545 de 20/05/93. Norma Operacional Básica 01/93. Brasília, DF: MS.

MS (Ministério da Saúde), 1997. Portaria MS no 2.203. Norma Operacional Básica/SUS. № 01/96. Brasília, DF: MS.

NETO, J. M., 1991. Políticas de saúde no Brasil: A descentralização e seus atores. Saúde em Debate, 31: 54-66.

O’DWYER, G. C. \& MOYSÉS, N. M. N., 1998. Conselhos municipais de saúde: $\mathrm{O}$ direito de participação da sociedade civil? Ciência \& Saúde Coleti$v a, 3: 26-27$.

SILVA, L. A. M. \& RIBEIRO, A. C. T., 1984. Paradigma e Movimento Social: Por Onde Andam Nossas Idéi$a s$ ? Águas de São Pedro: Associação Nacional dos Pós-graduandos em Ciências Sociais. (mimeo.) 